\title{
Tocata-visual Aberta
}

\author{
José Luiz Kinceler \\ Aline Goedert Volkmer ${ }^{1}$
}

\begin{abstract}
RESUMO
O presente artigo aborda a proposta Tocata Visual Aberta. Esta visou criar espaços diferenciados de convívio onde os participantes pudessem experimentar novas relações, criar novos vínculos, tendo a música como suporte à forma relacional. O artigo, portanto, é o resultado teórico de uma prática em arte relacional em sua forma complexa que abordou as inter-relações dos participantes, suas reações ao inesperado e suas colaborações. Busca também dar ênfase à diferença entre o que esperávamos e o que realmente ocorreu.
\end{abstract}

Palavras-chave: Tocata - Música - Criatividade - Arte Relacional Complexa

\begin{abstract}
The present article is a critical review of the project "Tocata Visual Aberta". A project that tries to create diferencial places of relating, where people can discover new relations, creates new bonds, having music as a support for the relational form. The article is the theoric result of a practice in relational art in its complex form. It seeks to descibe the interrelations of the participants, there reactions to the unexpected, there colaborations. Also gives enphasis to the diference between what we expect that will happen and what actually happens.
\end{abstract}

Key-words: Tocata - Music - Creativity - Complex Relational Art

\section{INTRODUÇÃO}

O tema deste artigo é a proposta Tocata Visual Aberta, levada a cabo como parte integrante do projeto de pesquisa: "Vinho Saber - Arte Relacional em sua forma Complexa". Visa analisar as diferenças entre o que foi planejado e como realmente as coisas aconteceram. Cada Tocata teve características próprias de local, instrumentos e participantes. Portanto, procura demonstrar as diferenças de cada experiência e tenta buscar sugestões para as próximas. É de fundamental importância analisar essas diferenças para que erros não sejam repetidos e para que as próximas contem ainda mais com a participação.

Tocata Visual Aberta trata de um encontro musical aberto a qualquer participante, que tenha ou não experiência com a música. A idéia é criar uma espécie de brecha

\footnotetext{
${ }^{1}$ Projeto de Pesquisa: Vinho Saber-Arte Relacional em sua forma Complexa - CEART Orientador: José Luiz Kinceler, departamento de Artes Visuais Bolsistas: Aline Goedert Volkmer (PROBIC), Francis Albrecht Pedmonte (PROBIC) Acadêmicos: Helton Patricio Matias (Licenciatura em Artes Plásticas)
}

DAPesquisa, Florianópolis, v.3 n.5, p.027-038, 2008. 
temporal aberta ao convívio, onde as pessoas possam fugir por um curto período de tempo de suas rotinas e fazer algo diferente do seu dia a dia.

A proposta segue a trilha de muitos artistas que trabalham segundo a ótica de uma forma relacional, preocupada com a participação das pessoas, sugere um momento de interação que seja capaz de transformar pelo menos por um período curto de tempo a experiência de cada participante. Esta forma relacional segundo Nicolas Bourriaud (2001) possibilita o encontro da arte com seu público. Para este autor trata-se de "uma arte que toma por horizonte teórico a esfera das interações humanas e seu contexto social" e que tem a propriedade de reunir sujeitos dentro do espaço institucional da arte em ações momentâneas e participativas.

Projetos que buscam a interação, a colaboração, e a convivência vêm acontecendo em arte desde a década de 60. Basta lembrar artistas como Helio Oiticica, Gordon Matta Clark, Joseph Beuys, e mais recentemente os projetos colaborativos de Rirkrit Tiravanija, Superflex, o projeto Quietude da Terra de Francis Morrin, Park Ficcion e muitos outros, que tentam articular processos artísticos de forma complexa. Nestes exemplos, a hibridização entre criatividade, educação, espiritualidade, economia, etc. Promovem outras relações entre as pessoas e novas formas de fazer este mundo mais interessante e digno de ser experienciado. Todos buscam através de seu trabalho realmente mexer com as relações entre pessoas, se relacionar com elas, fazer com que o momento passado ao lado delas se torne importante, muitas vezes a própria essência do trabalho.

A idéia é justamente multiplicar essas tentativas, essas brechas. Não deixá-las acontecer só uma vez ou outra, mas fazê-las uma nova forma de encarar a vida, que o fato de vivenciá-las possa aos poucos produzindo novas subjetividades. Se cada vez mais espaços para a convivência realmente humana existirem, talvez um dia não precisem mais ser gerados, pois farão parte da vida.

No livro TAZ: zona autônoma temporária, Hakim Bay teoriza de forma brilhante sobre esses pequenos momentos de escape que conseguem de alguma forma repensar a vida. Criar brechas, portos de liberdade em meio a um mundo controlado:

Estamos nós, que vivemos no presente, condenados a nunca experimentar a autonomia, nunca pisarmos, nem que seja por um momento sequer, num pedaço de terra governado apenas pela liberdade? Estamos reduzidos a sentir nostalgia pelo passado, ou pelo futuro? Devemos esperar até que o

DAPesquisa, Florianópolis, v.3 n.5, p.027-038, 2008. 
mundo inteiro esteja livre do controle político para que pelo menos um de nós possa afirmar que sabe o que é ser livre? (pg.13)

Embora o livro siga uma linha mais política, é importante ressaltar a necessidade de liberdade nos dias de hoje. Não temos momentos livres, sem controle, sem preocupações, sem regras. É justamente esse tipo de momento, de situação que tentamos criar. Através da improvisação criamos uma música sem regras, livre, uma música que nos faz esquecer nossas preocupações e nossas regras, e nos inspira talvez a viver realmente essa liberdade aqui e agora.

Uma vez que o Estado se preocupa primordialmente com a Simulação, e não com a substância, a TAZ pode, em relativa paz e por um bom tempo, "ocupar" clandestinamente essas áreas e realizar seus propósitos festivos. (pg. 17-18) 3

Sendo que essa área ocupada, como o próprio Bey coloca numa passagem anterior pode ser um pedaço "de terra, de tempo, de imaginação". A Tocata Visual Aberta como proposta visa agir justamente no sentido da imaginação liberando a mente através da experimentação com a música.

A música foi escolhida como um meio para fazer com que as pessoas experimentem com liberdade. Com liberdade não quero dizer uma liberdade total e irrestrita, digo liberdade dentro de relações de convívio, pois embora todos tenham usado o mesmo material, tivemos liberdade quanto a pequenos detalhes, como formato, tamanho e essas escolhas levaram a instrumentos com sons completamente diferentes. Também nas Tocatas haviam restrições, ou escolhas pé estabelecidas, como o local, o número e variedade dos instrumentos disponibilizados, e assim sucessivamente. Mas havia total liberdade de escolha em participar, não participar, assistir, dançar, cantar, contribuir ou não da maneira que desejasse. É ai que se enquadra a liberdade, a liberdade de escolher o que fazer frente a circunstâncias pré-estabelecidas e criar algo novo a partir de premissas já estagnadas.

\footnotetext{
${ }^{2}$ BEY, Hakim. 2001(ver bibliografia)

${ }^{3}$ Idem 1 .
} 
O conceito de liberdade é algo que já foi discutido incansavelmente por pensadores ao longo dos tempos, a existência ou não da liberdade. Se tivermos realmente poder de escolha ou se isto seria apenas uma ilusão que criamos para dar sentido a nossa vida. Rudolf Steiner, criador da pedagogia Waldorf ${ }^{4}$, aborda largamente esse tema em seu livro $A$ Filosofia da Liberdade. Demonstrando os dois lados dessa discussão, e tentando chegar a uma espécie de meio termo. Já que não podemos dizer que todas as escolhas sejam livres, pois muitas provêm de pulsões que são para nós de certa forma inevitáveis.

Ninguém duvidará de que a criança não é livre quando exige o leite, e tampouco o bêbado ao pronunciar coisas das quais mais tarde se arrepende. Ambos não sabem nada das causas que atuam nas profundezas de seus organismos e da coerção irresistível que elas exercem sobre eles. Porém é realmente lícito confundir ações desse gênero com outras nas quais o homem não é somente consciente de seu agir, mas também sabe das causas que o movem? Será que as ações dos homens são todas do mesmo gênero? Será que é válido equiparar, cientificamente, as ações do guerreiro no campo de batalha às do pesquisador científico no laboratório ou, enfim, as do político em complicados assuntos diplomáticos, à da criança que quer o leite? (pg.5)

Poranto quando utilizo a palavra liberdade devo esclarecer que a entendo como a escolha dentro de parâmetros pré determinados que parta da reflexão da pessoa em questão, ou de sua própria individualidade. Ou seja, um ato criativo que transborde o que seria esperado.

Aqui também serão analisados outros resultados do projeto, como a produção do site, de um DVD e de um CD com gravações das Tocatas.

\footnotetext{
${ }^{4}$ Para um entendimento mais profundo da pedagogia, ver LANZ, Rudolf . A pedagogia Waldorf: caminho para um ensino mais humano, o livro explica de forma simples a pedagogia. Para uma leitura mais completa são recomendados os dois livros de Rudolf Steiner listdos na bibliografia

${ }^{5}$ STEINER, Rudolf. A Filosofia da Liberdade.(ver bibliografia)
} 


\section{O Projeto}

Tocata Visual Aberta é uma proposta que visa a criação de um espaço de encontro, onde as pessoas podem interagir de formas diferentes e experimentar novas formas de convivência através da música.

A idéia era de criar um espaço móvel, uma descontinuidade temporal com o outro, onde pessoas pudessem se encontrar e experimentar a música com instrumentos diferentes, instrumentos sem regra, e fazer da Tocata uma música coletiva sem partitura, improvisada. Que este espaço ao mesmo tempo em que causasse certo incomodo por estar fora do lugar, pudesse ser incorporado e se tornar uma espécie de dimensão alternada de tempo e espaço do lugar que ocupasse. Um lugar que poderia existir em cada um que compartilha da experiência de estar ali.

Nosso mundo está cheio de pessoas-máquina, cada vez mais precisas, cada vez mais rápidas. Cada dia que passa precisam de menos contato com outras pessoas, cumprem suas funções sozinhas e não se interessam pelos outros. Passam a vida correndo atrás de sua especialização pessoal e no fim o que fizeram? O que viveram? Seguem o fluxo e passam, nada muda e o mundo segue seu rumo cada vez mais eficaz e mais produtor. Onde estão as belas noites de canções, de danças, de conversa?

A idéia da proposta era de certa forma reverter essa situação e criar espaços para um convívio diferenciado, que se enquadrasse como quebra do cotidiano. A idéia do projeto é tentar fazer com que as pessoas divirtam-se, espantem-se, sintam algo diferente do que a rotina diária proporciona. É criar espaço para que surjam aqueles momentos que muitos de nós já passamos, de esquecer o mundo. Aqueles momentos musicais mágicos que começam com certa timidez, mas que aos poucos vão ganhando força.

A primeira etapa do projeto foi destinada a produção dos instrumentos. Para tanto durante o segundo semestre de 2007 desenvolvemos uma oficina de cerâmica para produzir djambés e ocarinas e instrumentos de corda, processo que era aberto a qualquer interessado.

Foram trabalhados em argila de forma que cada um pôde colocar um pouco de si em seu instrumento. Esse processo ajuda a se soltar, pois os instrumentos estão ali para serem experimentados. Eles apresentam um conjunto de possibilidades sonoras para serem testadas e construídas ao longo do processo.

Assim, o processo começou com a criação de instrumentos não padronizados. 
Instrumentos criados por cada participante com carinho, nascidos de dias de trabalho em argila. Trabalhando em grupo, um ajudando e ensinando o outro, conversando, brincando e convivendo. Cada instrumento tinha um som diferente, número de cordas diferentes, formas de tocar diferentes, de forma que cada um pôde descobrir como tocá-lo de uma nova maneira. Não existiam regras, cada um pôde construir como queria e depois vimos o resultado. Ajudamos um ao outro na hora da construção da peça, para que cada instrumento ficasse estruturado para ser queimado.

Estes instrumentos foram levados até a comunidade da servidão Batuel Cunha, no Rio Tavares, onde fizemos uma grande festa enquanto as peças queimavam no enorme forno. Enquanto colocávamos lenha, brincávamos, tocávamos, todos juntos, sem preocupações, apenas querendo transformar um trabalho em algo prazeroso e consciente.

No semestre seguinte iniciamos as Tocatas propriamente ditas. Escolhemos o CEART como espaço inicial para as Tocatas. Acreditávamos que seria bom criar um meio de interação entre os cursos, uma forma de interação que envolvesse todas as artes. Queríamos que qualquer aluno se sentisse convidado a participar, que houvesse algo de atraente para todos. Pois quanto mais variada fosse a participação, mais ricos seriam os encontros e as trocas.

Para incentivar os outros fizemos uma roda com os instrumentos musicais, muitos dos quais haviam sido feitos na oficina. Começamos a tocar esperando que as pessoas percebessem e viessem participar. Havíamos colocado instrumentos de captação de som para que pudéssemos gravar o que acontecia.

Com o passar do tempo não temos mais consciência de sermos separados do todo, a única coisa que sentimos é uma sensação orgânica, de uníssono, uma junção de todos aqueles indivíduos únicos em uma grande música. Mas é uma música que nos preenche não apenas os ouvidos, mas também os olhos, pois olhamos à nossa volta e vemos pessoas diferentes, algumas desconhecidas outras conhecidas, tocando instrumentos que pareciam ser uma extensão de nós mesmos.

A música se tornou cada vez mais contagiante. Aos poucos cada um se acostumava com a presença do outro, e todos começavam a ouvir o outro e saber o que fazer e quando. As músicas se tornaram complexas, se desdobraram. De um momento para o outro percebemos que aquilo nunca poderia se repetir, que aquele momento era único, que aquela música ficaria guardada apenas em nós sem possibilidade de reprodução. Pois a gravação 
do som não é capaz de reproduzir a sensação do momento, nem as danças, as interações.

Essa impossibilidade de reprodução inicialmente nos entristeceu, mas começamos aos poucos a ver como a música brota do momento, e a repetição daquele momento não seria nem de longe a mesma experiência. É justamente a junção do momento de cada um que torna aquilo possível, a vontade de cada um de improvisar, de se soltar, de esquecer se sabe ou não tocar, se sabe ou não cantar e se entregar as mais profundas pulsões melódicas e rítmicas de seu próprio ser.

Quando pegamos o instrumento pensamos mais no individual, prestamos atenção em nossos dedos, conseguimos perceber quem toca bem, quem não toca, mas é no momento que pensamos no coletivo que temos o momento mais sublime, me lembra de certa forma um cardume de peixes, ou um bando de aves que se movimenta com harmonia total sem nenhuma pré-combinação. É no momento que esquecemos que nossos dedos estão ali que a música começa a nos envolver como um todo.

A proposta não tinha outras pretensões além de causar esse encontro, esse espaço de vida que se perdeu, essa parte que não precisa ter um fim específico, uma produção final, apenas continua em quem participou e talvez na vontade de criar mais encontros

Fizemos muitas dessas experiências, alternamos o espaço, os instrumentos, e cada Tocata era completamente diferente devido à contribuição que variava e diferenças entre as pessoas. Algumas tocatas foram mais vazias, outras foram mais lotadas. Em algumas fizemos projeções simultâneas de vídeos, o que foi extremamente interessante, pois os vídeos pareciam ser fonte de inspiração para o ambiente.

A idéia de projetar vídeos veio de uma necessidade de compartilhar conteúdos diferenciados ao longo dos encontros. Com os vídeos acabamos provocando um interesse maior nas pessoas. Além disso, a projeção trazia para a tocata um aspecto de experimentação não só sonora, mas também visual. A partir deste momento alteramos o de Tocata Aberta nome para Tocata Visual Aberta. Vimos que muitas coisas poderiam ser unidas à idéia original e que não precisaríamos restringir a experimentação a apenas um âmbito sensorial. Quanto mais aspectos fossem englobados, mais rica ficaria a experiência.

Algumas Tocatas tiveram características um pouco diferentes, eram mais “eletrônicas", pois contavam com a presença de instrumentos amplificados como guitarra, baixo, bateria e microfones. Embora esses instrumentos tenham trazido um toque diferente também cobriam um pouco o som dos instrumentos acústicos, de forma que nessas tocatas 
não era tão fácil esse entrosamento entre todos os participantes. Era difícil não seguir os instrumentos mais altos o que dificultava um pouco a troca, a contaminação. Mesmo assim em alguns momentos surgiram sons que correspondiam ao encantamento dos que ali estavam colaborando.

A última Tocata no dia 19 de Junho foi uma das mais bem sucedidas no aspecto de integração, as músicas ficaram muito ricas e todos conseguiam se ouvir melhor, o que facilitou muito a integração dos instrumentos. Não utilizamos muitos instrumentos amplificados e os que estavam amplificados tinham um volume mais ameno que nas anteriores. Com esse equilíbrio sonoro acabamos chegando a resultados riquíssimos e muito harmoniosos.

A Tocata é uma forma diferente de experimentar a música, não é necessário saber tocar, nem entender de música, a idéia é simplesmente compartilhar uma experiência diferente e a música é simplesmente o meio que permite essa experiência. Para alguém que ouvisse apenas os resultados sonoros, talvez fosse difícil entender uma tocata como música. Talvez a reação fosse semelhante a alguém acostumado com música popular ao ouvir música erudita contemporânea, cheia de dissonâncias e coisas que parecem não fazer sentido. Aqui creio que caiba citar um trecho do texto de Iban Urizar sobre o embate entre musica experimental e música contemporânea:

En música contemporánea existe la figura del analfabeto musical, ese que no entiende de disonancias ni de ciencia musical, ni es capaz de comprender la evolución de la historia musical. Su discurso es rechazado por ineptitud. No sabe de música, por lo tanto es como si estuviera sordo. (p.2)

A Tocata, porém, diferentemente da música contemporânea, não necessita nada para ser entendida além da participação. Pois é no momento da participação que aqueles sons fazem sentido, quem escuta apenas uma gravação não tem como sentir a música da mesma forma. Também quem apenas escuta não tem como imaginar o momento, as pessoas, as projeções, as danças, muita da riqueza original se perde. Este foi um dos motivos que nos levou a registrar alguns momentos de algumas Tocatas com imagem, fotos e vídeos, para que pudéssemos ao menos ter um registro destes outros aspectos.

Um dos aspectos interessantes desses registros é que eles potencializarão a proposta de uma forma virtual. Os sons gravados serão disponibilizados no site Vinho Saber para DAPesquisa, Florianópolis, v.3 n.5, p.027-038, 2008. 
que qualquer um possa baixar e modificar, da forma que achar interessante. Com isso podemos criar uma rede virtual de interação e colaboração sem direitos autorais, de forma que nesse espaço virtual surja uma nova forma de interação que venha a enriquecer a proposta.

Temos também a intenção de mandar as músicas diretamente para compositores e artistas que se interessem por esse tipo de vivência, para que conheçam o trabalho e quem sabe utilizem alguma idéia em suas próprias composições, ou simplesmente contribuam com alguma nova idéia. Queremos compartilhar irrestritamente o que criamos em conjunto, para que essa criação cresça para um grupo cada vez maior de participantes e se desdobre cada vez mais.

O fato de isso ser encarado como arte ou não na verdade não importa, pouco importa a caixa em que queiramos inserir uma coisa ou outra, a idéia é justamente trazer tudo à tona e misturar. Porque não aprender musica com matemática, com arte, com história? Porque dividir tudo em caixotes e esquecer que no mundo nada é tão claro, tão preciso, o mundo é completamente diferente de uma máquina cheia de peças previsíveis e precisas.

De uma forma ou de outra queremos todos chegar a um novo paradigma, um paradigma que nos permita viver de forma mais completa, mais livre. E se não conseguirmos pelo menos aproveitamos bem nosso tempo tentando.

\footnotetext{
${ }^{6}$ URIZAR, Iban. 2008 (ver bibliografia)
} 


\section{Conclusão}

A proposta visou basicamente propiciar o encontro entre pessoas através da música. Reinventar seu cotidiano. Um momento de encontro subtraído de seus cotidianos para simplesmente conviver.

Num mundo com tanta sobrecarga de informações, com tantas novidades, as vezes é difícil tirarmos alguns minutos para viver novas experiências, conhecer novos horizontes. Viver com um pouco mais de liberdade, aventurar-se sem medo pelo desconhecido.

Ao invés de tentar transformar o mundo, tentar reinventar nossos próprios valores e relações, nem que seja apenas por curtos períodos de tempo. Pois se cada um de nós for mudando aos poucos, ou pelo menos tirando um pouco de tempo para coisas novas, um dia quem sabe o mundo será um pouquinho diferente, pelo menos para algumas pessoas.

Creio que o processo tenha sido bem sucedido até esse ponto, foi um pouco mais restrito que imaginávamos, já que acabou sendo quase sempre dentro do campo da UDESC e os instrumentos não tenham variado muito. Mas apesar disso creio que tenha dado um pontapé inicial para muitos novos desdobramentos e idéias. O próprio site onde todos podem colaborar com as músicas sem se preocupar já é um novo desdobramento que ainda percorrerá muitos caminhos. Esperamos também que surjam novas Tocatas espontâneas, que surjam da vontade de se encontrar. Que essas tenham sido apenas o ponto inicial para muitos novos encontros.

Neste artigo tentei traçar um mapa dos possíveis rumos que esse projeto pode vir a seguir, pois ele não acaba aqui, ele continuará a se desdobrar de forma inesperada. É justamente esse inesperado que interessa, o incalculável, a parte que não podemos prever. Pois se tudo corre sempre como esperamos não aprendemos nada novo. As coisas se tornam obsoletas se seguem um rumo pré-determinado sem por um segundo sequer questionar este rumo. Temos aqui descrita apenas uma possibilidade de rumo, pois apenas depois da viagem é que podemos sentar em roda e descrever com detalhes cada aventura. Mas uma coisa sempre podemos garantir, que nunca será como planejamos.

\section{Referências Bibliográficas}

BEY, Hakim. TAZ: zona autônoma temporária. São Paulo: Conrad Editora do Brasil, DAPesquisa, Florianópolis, v.3 n.5, p.027-038, 2008. 
2001.

BHABHA, Homik . Conversational Art. In: JACOB, Mary Jane, e BRENSON, Michael (eds.) . Conversations At the Castle: Changing Audiences and Contemporary Art . Cambridge, Massachusetts: the MIT Press, 1998.

BISHOP, Claire . Participation . (Introduction//Viewers as Producers, pg.10-17) Cambridge, Massachusetts: the MIT Press, 1998.

CERTEAU, Michel de, De las prácticas cotidianas de oposicion . In: BLANCO, Paloma; CARRILLO, Jesús; CLARAMONTE, Jordi, e EXPÓSITO, Marcelo (ed.) Modos de Hacer: Arte critica, esfera pública y acción directa . Ediciones Universidad de Salamanca, 2001.

BOURIAUD, Nicolas, La Forma Relacional . In: BLANCO, Paloma; CARRILLO, Jesús; CLARAMONTE, Jordi, e EXPÓSITO, Marcelo (ed.) Modos de Hacer: Arte critica, esfera pública y acción directa . Ediciones Universidad de Salamanca, 2001.

BOURRIAUD, Nicolas . Estética Relacional . Buenos Aires: Adriana Hidalgo editora, 2006.

BUCHLOCH, B.; CRIADO, N.; GUIDIERI, R.; HANHARDT, J.G.; JAUSS, H.R.; e TRÍAS, E. . El nuevo espectador In: JIMÉNES,J. (ed.), Fundacion Argentina: Visor Dis., 1998.

CROW, Thomas. The Rise of the Sixties: American and European Art in the Era of Dissent . (Cap.6- “1969”, pg. 159-181), Yale University Press, 2004.

CROW, Thomas . Unwritten Histories of Conceptual Art . In: ALBERRO, Alexander; BUCHMANN, Sabeth. Art After Conceptual Art . Cambridge, Massachusetts/ London, England : the MIT Press, 2006.

PINEUS, Robert L. The Invisible town Square: Artist's Collaborations and Media Dramas in America's Biggest Border Town . In: FELSHIN, Nina (ed.) . But is it Art? :The Spirit of Art as Activism . Seattle: Bay Press, 1994

FOUCAULT, Michel . Estética, Literatura e Pintura, Múscia e Cinema (Outros espaços, pg.411-422) Ditos e Escritos volume III . RJ, Forense Universitária, 2001.

KESTER, Grant H. . Conversation Pieces: Community and Communication in Modern Art . (cap.5- Community and Communicability, pg. 152-171) . University of California Press, 2004.

KWON, Miwon . One Place After Another: Site-Specific Art and Locational Identity . (Cap.1 e 4), Cambridge, Massachusetts: the MIT Press, 2002. 
LADDAGA, Reinaldo, . Estética de la emergencia . Buenos Aires: Adriana Hidalgo editora, 2006.

LANZ, Rudolf . A pedagogia Waldorf: caminho para um ensino mais humano . 7. ed. São Paulo: Antroposofica, 2000.

STEINER, Rudolf . A educação da criança: segundo a ciência espiritual . São Paulo: Antroposófica, 1984.

STEINER, Rudolf . A Filosofia da Liberdade: Fundamentos para uma filosofia moderna . São Paulo: Antroposofica, 1983.

STEINER, Rudolf . Andar, falar, pensar . São Paulo: Antroposofica, 1983.

Periódicos:

CADERNO VÍDEOBRASIL 02:

DIELEMAN, Hans . Sustentabilidade como Inspiração para a Arte: um pouco de teoria e uma galeria de exemplos . (pg.119-133).

KURT, Hildegard . Arte e Sustentabilidade: uma relação deafiadora, mas promissora. (pg.135-143).

ARTE EM REVISTA - Ano 5 - Número 07 (Agosto de 1983):

MORAES, Frederico . O corpo é o motor da obra . (pg.47-52).

BRITO, Ronaldo . Malas Artes: um depoimento pessoal (pg.53). 